\title{
REVIEWS.
}

\section{CHRONIC NASAL SINUSITIS AND ITS RELATION TO MENTAL DISORDERS.}

By F. A. Pickworth, B.Sc., M.B., B.S., A.l.C. London: 1935. Price 16/-.

The aim of the author of this monograph is to demonstrate : firstly the existence, extent, and complications of chronic nasal sinusitis occurring in mental hospital patients; and secondly the mechanisms by which such chronic disease results in those physical changes of the brain tissue which are present in cases showing symptoms of mental disorder. The researches described in this book were carried out in the laboratories of the Joint Board of Research for Mental Disease at the Hollymore Mental Huspital, Birmingham. The theory of the Birmingham School is that psychotic states are attributable in many cases to hidden sources of infection. Such foci have been traced to the colon, cervix, ear, teeth, tonsils and nasal sinuses. Dr. Pickworth has for some time carried out interesting researches which he claims definitely show that an infected sphenoidal sinus mav spread from the sinus into the cranial carity. He suggests, furthermore, that the symptoms observed in many cases in which sphenoidal infection has been demonstrated might be attributable to a secondary involvement of the pituitary gland. It would seem that a sphenoidal infection may in certain circumstances affect the pituitary-hypothalmic region of the brain even though no macroscopic perforation of the pituitary fossa is present. In chronic psychotic patients the postmortem findings were as follows : Caries of the sphenoid bone; thickening of the dura mater; thickening and polypoid condition of mucous membrane of the sphenoidal sinus; and much involvement of the pituitary gland in the septic process.

Dr. Pickworth is to be congratulated for his painstaking and suggestive researches. At the same time it must be said that psychiatrists find it difficult to accept the view that focal sepsis is by any means the causal factor in the majority of psychotic patients. As far as we know no statistical statement has been given in regard to the recovery rate of those patients who have been treated for focal infections and, of course, many patients recover who have not received or required such treatment. It is somewhat difficult to accept the view put forward by Dr. Pickworth that " hysteria should be treated as a medical disease due to minute focal lesions and not due solely to 'the imagination.', '

The merit of the theory put forward in this monograph would seem to be its insistence on the need for submitting every psychotic patient to a thorough medical examination-for a healthy body may do much to stimulate a more healthy state of mind.

\section{SHORTER SURGERY.}

By Hamilton Bailey and R. J. McNeili

Love. Messrs. H. K. Lewis. 1935. Price $30 \%$ -

It was with the pleasant anticipation of a surgical " treat" that I began the review of the " Shorter Surgery" by those experienced and brilliant surgeons, Hamilton Bailey and R. McNeill Love. This was further sharpened on reading in the preface "that time-honoured shiboleths have been excluded.",

The chapters on tumours, neck and abdomen are very well written.

It is interesting to note that the authors still favour the older treatment of hæmorrhoids by pure carbolic acid, whilst they refer to the injection of five per cent. carbolic acid in almond oil (used by most rectal surgeons) as a " tendency," thus rather under-rating its value.

It is somewhat disappointing that they do not clearly associate the name of $\mathrm{Mr}$. Ernest Miles with the invention and development of the abdomino-perineal excision of the rectum for carcinoma.

The two classical operations for the cure of inguinal hernia, originated independently by Halstead and Bassini, are dismissed in five lines, as compared with more than a page of small print devoted to the less common operation for femoral hernia. 
The chapter on the genito-urinary system is exhaustive and interesting; reference is made of the new method of transurethral diathermy of the prostate, and a brief description of granuloma inguinale is given.

The chapters on the head, spine and nerves are detailed. The Watson Jones method of treatment of fractured spine in hyper-extension is described and advised. The practical considerations are dealt with ably. The section on the nerve surgery of the sympathetic nervous system is clear.

About two hundred and twenty valuable pages are devoted to injuries and diseases of bones and joints, and the volume is closed by an admirable chapter with detailed operative directions on infections of the hand.

The numerous illustrations are of a very high standard; some of them are beautifully coloured plates, and many of them are unique. Most of the line drawings can easily be profitably reproduced by the examinee.

The volume is comprehensive, well written, and its theory and practice are upto-date. The authors are to be congratulated on its creation; it is a work of a high order. It seems to be the ideal book for the candidate who has passed the Conjoint examination, finished his first " house job," and is preparing for the B.S. In it, the practical surgeon wishing for an opinion on an unusual condition, will also find assistance.

The book is attractively and strongly bound, indicating that the publishers anticipate hard usage by the student. The print is clear and the paper smooth. The price is thirty shillings; it is good value.

\section{SOME NOTABLE EPIDEMICS.}

By H. Harold ScotT, M.D., F.R.C.P. (Lond.), D.P.H., D.T.M. and H. (Camb.), F.R.S.E., with a Preface by Professor W. W. Jameson. Edwin Arnold \& Co. 1934. Price 12/6 net.

During the last seventy to eighty years there have been published, mostly in official volumes, many reports on subjects relating to public health, an acquaintance with which is of the highest importance as much to the administrator as to the student. Notable amongst them are detailed accounts of outbreaks of the communicable and preventable, diseases. Yet, except in the case of the most recent, these reports are not easily come by. Many are out of print and are to be consulted only in certain libraries at the sacrifice of valuable time. It is true that the conclusions reached by the investigators in the case of the most important of these enquiries are to be found in the larger treatises on hygiene and state medicine; but even in such works little or no room is available for descriptions of the lines of research followed, methods employed and pitfalls avoided in those instances in which the problems, often intricate, that presented themselves, were successfully solved. And it is just the knowledge of these details that is so essential to the person who finds himself confronted with the elucidation of similar questions. Further, even if access to the reports referred to has been afforded to the enquirer, it is usually a matter of much time and labour to extract from the mass of evidence exactly what is necessary for guidance in practice.

In order, therefore, to lighten the task of those who are interested in the methods of epidemiological enquiry, Dr. Scott has summarized from the official reports and set forth in a succinct yet interesting form the histories of some twenty to thirty epidemics of infectious diseases from the celebrated "Broad Street Pump" epidemic of cholera in 1854 to the curious "Pease Pudding" outbreak of Sonne dysentery in St. Pancras and Holborn in 1933. His selection of epidemics as "notable" has been made with the object of illustrating special points in the history of epidemiological investigation, as, for instance, the severe recurrence of the epidemic of enteric fever in Worthing in 1893 after it had been concluded that the worst was over. To these histories Dr. Scott has added a running commentary of his own, which his personal experience of epidemiological investigation renders the more valuable. We are of the opinion that he has been eminently judicious in the selection and happy in the presentation of his material. His book should prove of the greatest assistance to medical officers and students of public health. We recommend 